\title{
Cícero e a obra filosófica em latim como munus rei publicae
}

Sidney Calheiros de Lima Universidade de São Paulo sidneycalheiros@gmail.com

RÉSUMÉ: Dans les préambules de quelques unes de ses oeuvres philosophiques, surtout de celles publiées à partir de 45 avant J.C., Cicéron justifie son activité d'écrivain de philosophie en latin en caractérisant son travail comme un munus rei publicae. Dans ce texte, nous proposons que ce genre d'argumentation n'est pas seulement une stratégie rhétorique qui aurait en vue tout simplement la sympathie des lecteurs romains; il s'agit aussi d'une déclaration d'un grand projet d'éducation philosophique des hommes publiques romains, plusieurs fois évoqué dans l'oeuvre cicéronienne et qui se trouve en parfaite harmonie avec les aspects les plus profonds de la pensée de cet auteur.

MOTS-CLÉS: Cicéron; philosophie; philosophie hélénistique; philosophie en latin; littérature latine.

O que Cícero pretende com suas obras de filosofia, ou ao menos aquilo que nessas obras se apresenta como objetivo almejado, eis algo a que temos acesso principalmente por meio de seus proêmios. Muitas das obras filosóficas do renomado autor romano se organizam como conjuntos de diálogos filosóficos. Se, por um lado, em alguns desses diálogos o autor representa a si mesmo como personagem (característica que ele reconhece ter sido explorada por Aristóteles em seus diálogos), ${ }^{1}$ por outro, é especialmente nos proêmios que podemos ouvir a voz que, em primeira pessoa, fala em nome do autor. A partir dessa persona, que se expressa como a responsável pela composição da obra, a qual, evidentemente, não deixa de ser também uma construção discursiva do próprio Cícero, podemos ouvir o que o autor tem a dizer a respeito de sua obra. É no proêmio que Cícero defende o trabalho que apresenta ao público, exaltando a função que uma obra filosófica em latim pode ter na sociedade em que vive.

No caso das obras constituídas por diálogos, o proêmio vai servir ainda para introduzir a situação mimética (ou as situações miméticas, quando se trata de mais de uma cena) em que se dará a discussão filosófica. E em composições de obras como o De finibus, por exemplo, tratado composto por três diálogos distintos a respeito da questão do finis, ou sumo bem, os múltiplos proêmios, que antecedem cada uma das situações miméticas particulares, agenciarão, além do mais, a unidade da obra, ao organizar os diferentes diálogos, tidos em tempos e lugares distintos, em torno de uma só questão

\footnotetext{
${ }^{1}$ Cf. Cícero, Ad Atticum, XIII 19, 4.
} 


\section{nuntius antiquus}

filosófica. O proêmio geral da obra, portanto, aquele que introduz o primeiro livro, além de estabelecer a situação ficcional do primeiro diálogo, deverá também apontar ao leitor as linhas gerais da discussão que se travará nos três diálogos que compõem a obra.

Sem perder de vista a multiplicidade de funções que os proêmios desempenham nas obras filosóficas de Cícero, algumas das quais apresentamos acima, pretendemos discutir, neste breve texto, um tema que, recorrente nos proêmios, recebe um tratamento mais extenso (e análogo) em duas obras que o pensador romano compôs em período bastante próximo e que foram dadas ao público quase que simultaneamente. Queremos tratar do projeto de constituição de uma filosofia em língua latina, conforme enunciado nos proêmios do De finibus e da segunda versão da Academica, textos de 45 a.C., ${ }^{2}$ sobretudo no que diz respeito a seu alegado caráter de serviço público prestado à sociedade romana e a sua relação geral com a postura filosófica de Cícero.

Tomemos como ponto de partida, porém, um importante trecho de outra obra ciceroniana, posterior às duas mencionadas acima. Trata-se da passagem introdutória do segundo livro do De diuinatione, de 44 a.C., em que o autor romano apresenta uma lista de suas obras até então publicadas. Após elencar o que até ali escrevera, a persona do autor nos revela um projeto audacioso:

Até aqui, foram essas obras. Ao que restava, com ardor nós nos dirigíamos, com tal disposição de ânimo, que, se nenhuma causa mais grave tivesse se colocado como obstáculo, não deixaríamos remanescer nenhum tópico de filosofia que não se tornasse acessível, abrilhantado em letras latinas. Pois que maior serviço ou mais excelente podemos realizar em favor da república, do que ensinar e instruir a juventude? $?^{3}$

Ora, de acordo com o texto, escrever filosofia em latim, tentando cobrir de modo amplo as várias questões tratadas por esse tipo de saber, constitui um projeto de educação. Se, de uma parte, por conta de suas razões estéticas e filosóficas, Cícero pretende illustrare a filosofia na língua latina, de outra, o empreendimento tem como finalidade franquear esse gênero de conhecimento aos seus concidadãos (locum esse... qui non Latinis litteris inlustratus pateret). Esse projeto educacional é, dessa forma,

\footnotetext{
${ }^{2}$ Para as datas de publicação das obras de Cícero, seguimos Raphael Woolf, tradutor e comentador da edição do De finibus preparada por Julia Annas e intitulada On moral ends. Cf. bibliografia.

${ }^{3}$ Cf. Cícero, De diuinatione II, 4: Adhuc haec erant; ad reliqua alacri tendebamus animo sic parati, ut, nisi quae causa grauior obstitisset, nullum philosophiae locum esse pateremur, qui non Latinis litteris inlustratus pateret. Quod enim munus rei publicae adferre maius meliusue possumus, quam si docemus atque erudimus iuиentutem? As traduções latinas são de minha autoria.
} 
considerado como uma espécie de serviço público (munus rei publicae), semelhante àquele que poderia prestar a seus concidadãos um sujeito que ocupasse um cargo na administração da cidade e das províncias ou na gerência de uma campanha militar.

Não resta dúvida de que a expressão desse projeto de confiar à língua latina os ensinamentos que até então só estavam disponíveis em grego é algo bastante presente nos textos filosóficos compostos por Cícero a partir de 45 a.C, como os Academica, o De finibus, as Tusculanae, o De Natura deorum etc., entretanto, nos proêmios de duas dessas obras, o De finibus bonorum et malorum e a versão final dos Academici libri, a questão da produção de uma filosofia em latim surge de maneira mais ampla e é tratada de modo mais cuidadoso. Não deixa de ser plausível pensar que isso se deva ao fato de que, com esses conjuntos de diálogos, Cícero inaugure, em sua obra, a discussão de partes mais teóricas da filosofia e cuja pertinência à vida cotidiana poderia não parecer tão evidente. Obras anteriores a 45 a.C., como o De re publica e o De legibus, ainda que tratassem de filosofia, ainda que abarcassem questões teóricas, discutiam assuntos diretamente voltados para a ação, para o negotium. Discutiam, com efeito, a melhor maneira de gerir uma cidade e as leis que a devem reger. O mesmo se pode dizer com relação às obras sobre arte retórica. ${ }^{4}$ Com os livros do ano de 45 a.C., Cícero daria início ao tratamento de questões aparentemente afastadas da vida prática, tarefa que, empreendida por um ex-cônsul no contexto cultural da Roma republicana da segunda metade do século I a.C, não poderia ser bem aceita, ao que parece, sem justificativa. Diversos testemunhos (vejam-se, por exemplo, os prefácios do historiador Salústio) levam-nos a considerar que, no contexto da moral tradicional romana (o mos maiorum), dentre todas as ocupações humanas, deveriam ser mais bem vistas aquelas que se voltassem para a coletividade e para a vida prática, de modo que as especulações teóricas, tão freqüentes em filosofia, poderiam não ser bem recebidas por todos.

Neste ponto, vale lembrar ainda que já no Hortênsio, também composto e publicado em 45 a.C., Cícero, como personagem, fizera uma exortação à filosofia numa representação mimética em que caberia ao seu ilustre rival detratar o estudo da filosofia

\footnotetext{
4 Argumentação desse tipo é desenvolvida, por exemplo, por Milton Valente (cf. A ética estoica em Cícero. Caxias do Sul: EDUCS, 1984). De todo modo, há que se levar em conta que, mesmo nas obras anteriores a 45 a.C., o autor parece revelar uma preocupação (que se pode observar também em outros autores de seu tempo, como mencionamos a seguir) em justificar os estudos e a atividade de escritor em face de outros modos de vida, como aquele devotado à ação, o modo de vida do homem público, o do chefe de estado, etc. Nesse sentido, a figura de Cipião, personagem central do De re publica, aparece como emblema de conciliação das tendências, aparentemente contraditórias, à vida contemplativa, por um lado, e à vida prática, por outro. 
em favor da formação retórica do homem público. Infelizmente, toda a querela tida entre as personagens de Cícero e de Hortênsio, representada no diálogo, nós só a podemos conhecer por meio de outros textos, ${ }^{5}$ pois esse protrepticus, tão admirado, como sabemos, por Santo Agostinho, e certamente por outros, não chegou até nossos dias. De todo modo, a própria existência de uma obra como o Hortênsio é índice claro, em nossa opinião, da necessidade de justificar o estudo de filosofia no contexto do fim da República romana. Se as questões desenvolvidas no Hortênsio, de uma parte, e nos proêmios do De finibus e da Academica, de outra, não são idênticas, parece razoável considerá-las contíguas, visto que a justificativa de uma produção de textos filosóficos em latim e de um projeto educacional que leve em conta a filosofia pressupõe a valoração da própria filosofia como saber digno do homem romano livre. 6

Pois bem, nos proêmios dessas duas obras que mais nos interessam e a que nos referimos acima, é dada voz aos que se contrapõem à composição de obras filosóficas em latim. Isso se dá, contudo, de modo distinto em uma e outra obra; na Academica, sob a forma de um diálogo entre duas personagens: Cícero, defensor da filosofia em latim e Varrão, que entende que seria um trabalho vão empreender tal tarefa; no De finibus, por meio da persona do autor, que se serve de uma figura de pensamento que consiste em antever os argumentos de possíveis opositores e rebatê-los de antemão, a anteoccupatio, como é chamada no De oratore (III, 205).

Do ponto de vista da argumentação, porém, os dois proêmios têm muito em comum. De modo geral, os mesmos argumentos são utilizados, com poucas variações, nos dois prefácios. Por vezes, ademais, determinado argumento, da forma como é apresentado em um, acaba por complementar ou elucidar um argumento utilizado no

\footnotetext{
${ }^{5}$ Cf. De finibus I 2: "Naquele livro em que, acusada e detratada por Hortênsio, a filosofia foi defendida e louvada por nós"./ Eo libro quo a nobis philosophia defensa et conlaudata est, cum esset accusata et uituperata ab Hortensio.

${ }^{6}$ Para evidenciar o caráter fundamental que tem a filosofia no amplo projeto educacional proposto por Cícero (que envolve a formação do homem público romano, a formação do orador), poderíamos citar diversas passagens, como as célebres falas de Crasso no primeiro livro do De oratore a respeito da cultura geral de que deve dispor o orador, ou todo o proêmio do Orator, em que o conhecimento filosófico é considerado essencial para a formação do eloquens. Contentamo-nos, entretanto, em mencionar um texto em que a relação de reciprocidade que o autor julga haver entre filosofia e retórica está representada de modo emblemático: "Com esse gênero de filosofia que nós seguimos, grande aliança (societatem) mantém o orador: pois toma emprestado da Academia a sutileza e, por sua vez, devolve-lhe a fecundidade de expressão e os ornamentos do discurso"./ Cum hoc genere philosophiae, quod nos sequimur, magnam habet orator societatem: subtilitatem enim ab Academia mutuatur et ei uicissem reddit ubertatem orationis et ornamenta dicendi. (De fato, 3)
} 
outro $^{7}$. Três aspectos parecem permear a questão da produção de textos filosóficos em latim nesses prefácios: um, mais geral, decorre da necessidade de justificar o projeto, demonstrando sua importância político-pedagógica; os outros dois surgem ao longo dessa justificativa: as preocupações estéticas do autor e as dificuldades inerentes à língua latina. Neste texto, conforme dissemos, devemo-nos ater apenas ao primeiro aspecto. O segundo, que diz respeito ao método de investigação filosófica utilizado por Cícero e de sua afinidade com a retórica, foi tratado por nós em duas seções de nossa tese de doutorado, à qual remetemos o leitor. ${ }^{8}$ A ela também remetemos o leitor com vistas a uma discussão mais ampla sobre o terceiro aspecto. Desse tema nós tratamos especialmente nas notas à tradução do De finibus que propusemos em nossa tese. ${ }^{9}$

No prefácio de Academica I (isto é, o primeiro livro da segunda versão), ${ }^{10}$ as personagens de Cícero e de Ático, que se acham na quinta de Cícero em Cumas, ${ }^{11}$ vão ao encontro de Varrão, que, vindo de Roma, acabara de chegar a sua quinta, não muito distante da de Cícero. O encontro ocorre na propriedade do autor do De lingua Latina (eis um importante elemento dos diálogos ciceronianos: eles têm lugar, geralmente, nas casas de campo das personagens, espaço em que, afastados da vida pública, esses

\footnotetext{
${ }^{7}$ Nesse sentido, é interessante recordar um interessante testemunho de Cícero a respeito da composição de seus proêmios. "A ti eu dediquei o livro sobre a glória. No entanto, nele o proêmio é o mesmo que o do terceiro livro acadêmico. Eis o acontece: é que tenho uma coleção de proêmios. Dessa coleção costumo escolher um, assim que começo algum syngramma"./ De gloria librum ad te misi. At in eo prohoemium idem est quod in Academico tertio. Id euenit ob eam rem, quod habeo uolumen

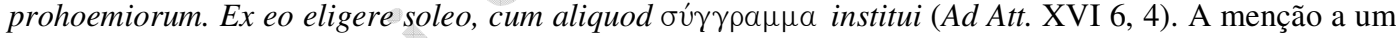
uolumen de proêmios revela muito da composição ciceroniana. Mostra-nos, por exemplo, como toda sua philosophica era pensada como um só e grande projeto. Por outro lado, a afirmação a respeito da identidade de proêmios em obras distintas deve ser nuançada. A identidade não poderia ser total. Ao menos não em todo e qualquer caso. Tendo em vista que os proêmios introduzem situações miméticas e matérias distintas, não poderiam ser assim completamente intercambiáveis. O que pode ocorrer (e, evidentemente, isso não passa de hipótese, uma vez que nem o terceiro livro da Academica nem o De gloria nos foram transmitidos) é que o tal uolumen contivesse apenas as porções dos proêmios que podiam se ajustar a toda e qualquer obra filosófica. Conteria, então, considerações mais gerais, como, por exemplo, a defesa de seu projeto educacional...

${ }^{8}$ Cf. de Lima, S. C. Aspectos do gênero dialógico no "De finibus" de Cícero. Campinas: UNICAMP, 2009 (sobretudo as seções In utramque partem: um método de investigação filosófica e O método ciceroniano e o diálogo).

${ }^{9}$ A controvérsia aparece de modo esparso ao longo do De finibus. Ressurge sempre que, quer por meio da persona do autor, nos proêmios, quer por meio de alguma das personagens, fazem-se comentários às opções de tradução para os termos gregos. A questão ganha maior vulto, entretanto, e é discutida de um modo mais sistemático, no início do livro III, quando a personagem de Cícero, conversando com Catão, o Jovem, expõe os procedimentos que adota no tratamento em latim dos conceitos da filosofia grega, em geral, e, em especial, da complexa terminologia dos estoicos.

${ }^{10}$ Sobre o processo de composição das duas versões da Academica, cf. Ruch, M. Le préambule dans les oeuvres philosophiques de Cicéron. Paris: Les Belles Lettres, 1958, p. 149-168 e Griffin, M. The composition of the Academica: motives and versions. In: Inwood, B.; Mansfeld, J. (org.). Assent \& argument. Studies in Cicero's academic books. Leiden/ New York: Brill, 1997a, p. 1-35.

${ }^{11}$ No litoral da região da Campânia, ao sul de Roma. 
homens podem dedicar seu ócio a discussões que não se voltam diretamente para a ação política). ${ }^{12}$ Após uma breve conversa, Cícero, negando-se cortesmente a perguntar sobre o De lingua latina, que sabe estar tomando muito tempo do amigo, volta-se a Varrão dizendo:

E Varrão responde:

No entanto, eis uma pergunta que, antes desta ocasião, jamais me veio à mente te fazer, mas agora, depois que me lancei a confiar aos textos aquilo que em tua companhia aprendi e a abrilhantar em letras latinas aquela antiga filosofia que se originou em Sócrates, pergunto por que, embora muito escrevas, deixas de lado este gênero de assuntos, sobretudo uma vez que nele tu próprio te destaques e uma vez que esse estudo e toda essa matéria estejam muito à frente dos demais estudos e artes? ${ }^{13}$

Perguntas algo sobre o que amiúde deliberei e muito refleti, de modo que não hesitarei ao responder, mas direi coisas que me vêm de imediato, pois precisamente a respeito desse assunto pensei muito, como eu disse, e por muito tempo. Pois vendo que a filosofia foi exposta em grego da forma mais cuidadosa possível, considerei que, se alguns dentre os nossos fossem cativados por tal estudo, se já fossem instruídos nos ensinamentos gregos, leriam as obras gregas de preferência às nossas; se, por outro lado, tivessem aversão pelas artes e doutrinas gregas, não se ocupariam, por certo, de coisas que, sem uma educação grega, não se podem compreender, de modo que não quis escrever o que nem os que não fossem doutos poderiam compreender nem os doutos se ocupariam de ler. ${ }^{14}$

${ }^{12}$ É um traço da representação mimética das obras de Cícero que está bem de acordo com o ambiente cultural em que ele viveu. Michel Ruch, que estudou a composição mimética dos diálogos ciceronianos, dedica uma seção para discutir o papel das uillae na composição cênica. $\mathrm{O}$ autor colhe evidências tomadas da correspondência de Cícero com o fito de defender o quanto as conversas representadas nos diálogos são ficções bastante calcadas em costumes da vida cotidiana do autor (cf. Ruch, op. cit., p. 8085). Essas propriedades de campo eram, para os optimates romanos, o lugar consagrado ao ócio. Assim, outro traço fundamental na mimese ciceroniana, que está ligado ao ambiente das villae, é o fato de a grande maioria das discussões representadas acontecerem em períodos de feriados, quando, na cidade, por conta das celebrações religiosas, as atividades do fórum e do senado ficavam suspensas.

${ }^{13} \mathrm{Cf}$. Academica I, 3: Illud autem mihi ante hoc tempus numquam in mentem uenit a te requirere. sed nunc postea quam sum ingressus res eas quas tecum simul didici mandare monumentis philosophiamque ueterem illam a Socrate ortam Latinis litteris illustrare, quaero quid sit cur cum multa scribas genus hoc praetermittas, praesertim cum et ipse in eo excellas et id studium totaque ea res longe ceteris et studiis et artibus antecedat.

${ }^{14} \mathrm{Cf}$. Academica I, 4: Rem a me saepe deliberatam et multum agitatam requiris. itaque non haesitans respondebo, sed ea dicam quae mihi sunt in promptu, quod ista ipsa de re multum ut dixi et diu cogitaui. nam cum philosophiam uiderem diligentissime Graecis litteris explicatam, existimaui si qui de nostris eius studio tenerentur, si essent Graecis doctrinis eruditi, Graeca potius quam nostra lecturos, sin a Graecorum artibus et disciplinis abhorrerent, ne haec quidem curaturos, quae sine eruditione Graeca intellegi non possunt. itaque ea nolui scribere quae nec indocti intellegere possent nec docti legere curarent. 
Após criticar alguns textos de filosofia escritos em latim que circulavam em Roma, obras de epicureus como Amafínio e Rabírio, Varrão retoma:

Nós, contudo, aos preceitos dos dialéticos e também dos oradores obedecendo assim como a leis, já que os nossos [isto é, os acadêmicos] julgam ser uma virtude essas duas faculdades, somos levados a utilizar inclusive palavras novas, que os doutos, como disse, preferirão buscar nos gregos, e que os não doutos não acolherão, nem mesmo vindas de nós, de modo que em vão nos encarregaríamos de todo o trabalho". ${ }^{15}$

E, um pouco mais adiante, conclui seu raciocínio:

"mas os meus amigos nos quais há esse interesse, mando-os à Grécia, isto é, exorto-os a irem aos gregos, para que antes bebam das nascentes do que andem à procura de pequenos regatos $(. .). "{ }^{\prime 16}$

A questão se coloca com a clareza típica do discurso ciceroniano: para que escrever filosofia em latim se já a temos em grego e de tal forma exposta que, imitá-la em latim seria como que criar uma pálida imagem do que já existe em grego? Quem se interessa por filosofia, não é mais proveitoso que busque as obras originais dos filósofos gregos? Aqueles que, por outro lado, não têm interesse no assunto, vão se ocupar em ler as obras filosóficas latinas, uma vez que sequer quiseram ler as gregas? A resposta é dada pela personagem que representa o autor, num trecho em que ele defende seu empreendimento tendo em vista a sua situação política e pessoal. Citamos:

Apresentas, por outro lado, um argumento que é, sem dúvida, persuasivo, pois ou preferirão ler as obras gregas os que forem instruídos, ou nem mesmo estas obras [as escritas em latim] os que aquelas desconhecem; mas me diz, agora: chegas a me convencer? Muito pelo contrário: não só lerão estas obras os que não podem ler aquelas, como os que podem ler as gregas não desprezarão as suas. Que motivo há para que os instruídos nas letras gregas leiam os poetas latinos e não leiam os filósofos? Acaso porque agradam Ênio, Pacúvio, Ácio e muitos outros que expressaram não as palavras, mas o sentido dos poetas gregos? Quanto mais agradarão os filósofos, se, assim como aqueles imitaram Ésquilo, Sófocles, Eurípides, da mesma forma façam com Platão, Aristóteles e Teofrasto. Entre os

\footnotetext{
${ }^{15}$ Cf. Academica I, 5: Nos autem praeceptis dialecticorum et oratorum etiam, quoniam utramque uim uirtutem esse nostri putant, sic parentes ut legibus uerbis quoque nouis cogimur uti, quae docti ut dixi a Graecis petere malent, indocti ne a nobis quidem accipient, ut frustra omnis suscipiatur <labor>.

${ }^{16} \mathrm{Cf}$. Academica I, 8: Sed meos amicos in quibus est studium in Graeciam mitto id est ad Graecos ire iubeo, ut ex [a] fontibus potius hauriant quam riuulos consectentur 
nossos oradores, ao menos, eu vejo serem louvados os que tenham imitado Hipérides ou Demóstenes. De minha parte (falarei, pois, francamente) enquanto a ambição, enquanto os cargos públicos, enquanto as causas, enquanto da república não só a preocupação mas ainda algum tipo de ocupação mantinham-me atado e preso a muitos deveres, conservava esses estudos em meu íntimo e, para que não se perdessem, renovava-os, quando era possível, pela leitura; agora, porém, não só ferido por tão grave golpe da fortuna, como desobrigado da administração da república, busco na filosofia a cura para minha dor e julgo ser esse o mais honroso deleite para meu ócio. Pois, ou isto é o mais apropriado para a minha idade, ou, se algumas coisas realizamos dignas de louvor, isto está sobretudo em harmonia com aquelas, ou ainda, nada de mais útil fizemos para a instrução de nossos concidadãos, ou, se as coisas não são assim, não vejo nada mais que possamos fazer. ${ }^{17}$

A personagem se mostra bastante lúcida e consciente da dificuldade de sua empresa. Preocupação muito semelhante é expressa pela persona do autor logo ao início do De finibus:

Eu não ignorava, Bruto, que, ao confiar às letras latinas assuntos de que haviam tratado, no idioma grego, os filósofos de mais sublime engenho e de requintada doutrina, este nosso trabalho ficaria sujeito a diversas críticas. (...) Haverá também uns, e estes por certo versados nas letras gregas, que, menosprezando as latinas, dirão preferir ocuparem-se com a leitura dos gregos. ${ }^{18}$

O autor latino está bem ciente de que sua obra não vai agradar a uma boa parcela dos leitores romanos, sobretudo aos que conhecem a filosofia grega; está bem ciente de que sua obra pode ser preterida à dos gregos, mas essa preocupação é posta de lado, diante da importância que teria esse seu trabalho para a formação dos romanos que não

${ }^{17}$ Cf. Academica I, 10-11: Causam autem probabilem tu quidem affers: aut enim Graeca legere malent qui erunt eruditi, aut ne haec quidem qui illa nescient. sed da mihi nunc: satisne probas? immo uero et haec qui illa non poterunt, et qui Graeca poterunt non contemnent sua. quid enim causae est cur poetas Latinos Graecis litteris eruditi legant, philosophos non legant? an quia delectat Ennius Pacuuius Accius multi alii, qui non uerba sed uim Graecorum expresserunt poetarum? quanto magis philosophi delectabunt, si ut illi Aeschylum Sophoclem Euripidem sic hi Platonem imitentur Aristotelem Theophrastum. oratores quidem laudari uideo si qui e nostris Hyperidem sint aut Demosthenem imitati. Ego autem Varro (dicam enim ut res est), dum me ambitio dum honores dum causae, dum rei publicae non solum cura sed quaedam etiam procuratio multis officiis implicatum et constrictum tenebat, animo haec inclusa habebam et ne obsolescerent renouabam cum licebat legendo; nunc uero et fortunae grauissimo percussus uulnere et administratione rei publicae liberatus doloris medicinam a philosophia peto et otii oblectationem hanc honestissimam iudico. aut enim huic aetati hoc maxime aptum est, aut his rebus si quas dignas laude gessimus hoc in primis consentaneum, aut etiam ad nostros ciues erudiendos nihil utilius, aut si haec ita non sunt nihil aliud uideo quod agere possimus.

${ }^{18}$ Cf. De finibus I, 1: Non eram nescius, Brute, cum, quae summis ingeniis exquisitaque doctrina philosophi Graeco sermone tractauissent ea Latinis litteris mandaremus, fore ut hic noster labor in uarias reprehensiones incurreret. Nam quibusdam (...) Erunt etiam, et ii quidem eruditi Graecis litteris, contemnentes Latinas, qui se dicant in Graecis legendis operam malle consumere. 
têm acesso à literatura grega. Por meio dessa argumentação o autor confere à sua obra o valor de um verdadeiro serviço público, no mesmo sentido do exercido por um magistrado que ocupa um cargo na administração, função que também ele poderia e desejaria desempenhar, não fosse a atual conjuntura da república.

Cícero serve-se ainda da comparação entre sua obra filosófica e o trabalho realizado pelos poetas latinos que cultivaram em Roma os gêneros dramáticos ${ }^{19}$ criados na Grécia e pelos oradores romanos que tomaram gregos modelos. ${ }^{20}$ Nesse sentido, seus diálogos e demais obras de filosofia, postas lado a lado com as produções poéticas e oratórias, contribuiriam para a ampliação da cultura letrada dos romanos.

Impedido de se dedicar ao bem comum em um cargo público, o que já fizera, segundo sua opinião, durante o tempo em que servira à república, Cícero passa a se dedicar da única maneira que lhe é possível agora: provendo à instrução de seus concidadãos. $\mathrm{Na}$ verdade, ele se serve dessa inatividade forçada para confiar às letras aqueles estudos que fizera desde a juventude e que guardava, ao longo de sua carreira política, para os momentos íntimos, para seus momentos de ócio (de que as conversas representadas nos diálogos filosóficos em que ele toma parte como personagem

${ }^{19}$ Embora cite-se Ênio, reconhecido autor também de epopeia, a ênfase no contexto dos Academica é dada à poesia dramática. No De finibus, por outro lado, ressalta-se a relação que existe entre Homero e Ênio (cf. De finibus I, 7: Locos quidem quosdam, si uidebitur, transferam, et maxime ab iis quos modo nominaui, cum inciderit ut id apte fieri possit, ut ab Homero Ennius, Afranius a Menandro solet.).

${ }^{20}$ Essa argumentação, que aproxima sua obra filosófica da produção dos poetas e oradores romanos e a coloca sob o signo da imitatio, aparece de modo bem semelhante no De finibus. Tendo em vista que não é o ponto central de nossa discussão, contentamo-nos em apresentar ao leitor uma tradução do texto do $D e$ finibus em questão. Citamos De finibus I, 4-6: "É, portanto, mais difícil satisfazer os que dizem menosprezar os escritos em latim. E é disto, primeiramente, que neles me admiro: por que não lhes agrada a língua materna nos mais graves assuntos, embora eles próprios leiam, de bom grado, peças de teatro vertidas literalmente do grego? De fato, quem é de tal modo quase que hostil ao nome romano, que despreze, ou não tolere, a Medeia de Ênio, ou a Antíopa de Pacúvio, porque diga se deleitar com as mesmas peças de Eurípides e deteste o que se escreve em latim? Diria alguém: 'que eu leia os Sinefebos de Cecílio, ou a Ândria de Terêncio, de preferência a ambas de Menandro?' Desses eu discordo de tal modo que, muito embora Sófocles tenha escrito a Electra da maneira mais excelente possível, julgo, contudo, que eu devo ler a versão ruim de Atílio (...). Ora, ser inteiramente ignorante de nossos poetas é próprio da mais inerte indolência ou do gosto mais delicado e difícil de contentar. A mim, ao menos, não parecem instruídos o bastante aqueles que desconhecem o que é nosso (...). Ora, se os gregos são lidos pelos próprios gregos a respeito dos mesmos assuntos, rearranjados de outra maneira, que motivo há para que os nossos não sejam lidos pelos nossos?"/ Iis igitur est difficilius satisfacere qui se Latina scripta dicunt contemnere. In quibus hoc primum est in quo admirer, cur in grauissimis rebus non delectet eos sermo patrius, cum idem fabellas Latinas ad uerbum e Graecis expressas non inuiti legant. Quis enim tam inimicus paene nomini Romano est qui Ennii Medeam aut Antiopam Pacuui spernat aut reiciat, quod se isdem Euripidis fabulis delectari dicat, Latinas litteras oderit? 'Synephebos ego', inquit, 'potius Caecili aut Andriam Terenti quam utramque Menandri legam?' A quibus tantum dissentio ut, cum Sophocles uel optime scripserit Electram, tamen male conuersam Atili mihi legendam putem. (...) Rudem enim esse omnino in nostris poetis aut inertissimae segnitiae est aut fastidi delicatissimi. Mihi quidem nulli satis eruditi uidentur quibus nostra ignota sunt. Quod si Graeci leguntur a Graecis, isdem de rebus alia ratione compositis, quid est cur nostri a nostris non legantur? 


\section{nuntius antiquus}

parecem ser um reflexo estilizado). A porção final de sua resposta a Varrão (Acad. I, 11) com os membros do discurso coordenados por meio de um acúmulo da conjunção aut (parafraseando: ou isso que agora fazemos é adequado à nossa idade, ou está em harmonia com o que até aqui fizemos, ou até mesmo, é o que de mais útil fizemos, ou, por fim, se eu estou errado, não há mais nada que possa fazer), cria a impressão de que a personagem que representa o autor, reconhecendo a força da opinião de seu interlocutor (cf. causam autem probabilem tu quidem affers (...) satisne probas? - Acad. I, 10), busca, ainda assim, um alento para a situação política a que foi reduzido. É como se ele dissesse: "mas alguma utilidade tem de haver para esse trabalho". Em outras palavras, alguma utilidade deve haver para o homem livre e culto na esfacelada república romana.

Ao zelo para com os seus concidadãos e à preocupação com a situação política da Vrbs vem se acrescentar um motivo de ordem inteiramente pessoal: a filosofia lhe serve como consolação para a dor que o acabrunha, causada pela perda recente de sua filha, evento referido por meio da expressão fortunae grauissimo percussus uulnere.

A maneira como Cícero dá novo valor à composição de filosofia em latim é notável: de atividade que carece de dignidade social, relegada a homens retirados da vida pública e, conforme a opinião avançada por Varrão, de pouca utilidade, frente à existência das obras gregas, ela passa a figurar, pelas circunstâncias, entre as poucas atividades honrosas a serem desempenhadas por um homem culto na Roma de César.

No De finibus, esse desejo de ainda fazer parte, de alguma forma, da vida pública, está também presente na justificativa que se dá à obra. De modo semelhante, o ócio dedicado à filosofia é equiparado às funções desempenhadas por alguém que participa da administração do Estado. Citamos:

Eu, de minha parte, uma vez que em meio aos trabalhos, às fadigas, aos processos do fórum, não me parece que tenha abandonado o posto em que fui colocado pelo povo romano, devo daqui por diante, sem dúvida, quanto mais puder, nisto também me empenhar: que, com o meu trabalho, dedicação e esforço, tornem-se mais instruídos meus concidadãos. ${ }^{21}$

Nessa passagem, a sua condição de autor de filosofia é comparada às suas antigas funções de advogado e de homem da administração pública. O termo

${ }^{21}$ Cf. De finibus I, 10: Ego uero, quoniam forensibus operis, laboribus, periculis non deseruisse mihi uidear praesidium in quo a populo Romano locatus sum, debeo profecto, quantumcumque possum, in eo quoque elaborare ut sint opera, studio, labore meo doctiores ciues mei. 


\section{nuntius antiquus}

praesidium (que tem forte conotação militar, pois que significa "força armada encarregada de guardar ou defender", "guarda, guarnição" e, por extensão, "posto, ou presídio" em que se estabelece uma força de proteção) cria uma clara conexão entre a sua atual atividade de escritor e as funções de defensor da república que teria desempenhado quando cônsul. A mesma salvaguarda que garantira à república, quando ameaçada por Catilina e seu seguidores, o autor julga garantir aos contemporâneos e às futuras gerações de romanos, que poderão, através de seu texto, ter acesso ao estudo da filosofia.

Interessante observar, a partir de testemunhos de autores posteriores a Cícero, o quanto o seu juízo foi acertado. A influência dos textos de filosofia do pensador do século I a.C. viria a ser sentida por muitos séculos e por toda parte onde houvesse leitores de latim. O já citado Agostinho lançou-se à filosofia, segundo ele próprio informa, após ter sido "persuadido" por Cícero, efeito da leitura do Hortênsio. ${ }^{22}$

Avançando um pouco mais em nossa discussão, gostaríamos de defender que, ainda que argumentos que busquem justificar a atividade intelectual sejam recorrentes também em outros autores do fim da República (como o já referido Salústio), a menção a um projeto de educação filosófica dos cidadãos romanos tratado como um serviço prestado à sociedade não pode ser encarado, no pensamento ciceroniano ao menos, como um mero tópos retórico que não almeje outra coisa que não a captatio beneuolentiae. Queremos dizer que, mesmo que tenha também essa função, coisa que não excluímos, trata-se de argumento que se apresenta em absoluta e profunda coerência como o pensamento mesmo do filósofo romano.

No De finibus, por exemplo, segundo entendemos, a questão pedagógica é fundamental. Esse texto, que trata dos princípios que regulam a ação humana, mostra uma preocupação evidente com a formação do homem romano. Essa preocupação, aludida de maneira bastante hábil mesmo por meio de elementos da composição mimética, está presente ao longo dos três diálogos que compõem a obra e, segundo nos parece, é decisiva na orientação acenada pelo autor em direção a uma solução razoável para a questão do finis.

No primeiro diálogo, dois jovens romanos, Torquato e Triário, conversam com Cícero. É o respeito à condição consular deste que leva os dois jovens a passarem pela

${ }^{22}$ O Hortênsio de Cícero é citado em diversas passagens da vasta obra de Agostinho. Uma passagem é, contudo, capital: trata-se de trecho das Confissões (III 4, 7), em que o autor revela a importância da obra de Cícero para sua devoção à sapientia e para sua conversão espiritual. 
quinta do famoso orador, onde transcorre a cena, com a finalidade de saudá-lo. Por outro lado, é o reconhecimento da condição de profundo conhecedor de filosofia, de que desfruta nosso autor (ao menos na representação que cria de si próprio), que faz com que Torquato peça sua opinião a respeito da filosofia de Epicuro. No segundo diálogo, a discussão entre Cícero e Catão, o jovem, acontece na biblioteca herdada pelo jovem Luculo. A controvérsia a respeito dos princípios da moral estóica é encetada por uma conversa preliminar a respeito da maneira como se deve educar o jovem órfão, cuja formação parece ter sido confiada tanto a Cícero quanto a Catão, embora a este caiba de fato a tutela legal. ${ }^{23}$ Quanto ao último diálogo, ele tem lugar em Atenas, no ano de 79 a.C.. Cícero representa a época de sua própria educação filosófica, mimetizando uma discussão em que, jovem ainda, auditor do filósofo Antíoco, entra em controvérsia com uma personagem mais velha, Pisão. Os dois amigos disputam a aprovação do jovem Lúcio Cícero, primo do autor da obra, cada qual tentando fazer com que o jovem seja cativado por uma doutrina filosófica distinta. O tema: a moral da antiga Academia e dos peripatéticos. A questão pedagógica faz parte, portanto, mesmo que por vezes apenas em alusão sutil, das três discussões particulares que compõem a obra.

Se, além disso, observarmos as discussões propriamente ditas, veremos que a preocupação com a formação do homem romano é fator decisivo na argumentação por meio da qual a personagem que representa o autor rechaça a filosofia de Epicuro, no livro II, e a dos estóicos, no livro IV. ${ }^{24}$

Com relação ao epicurismo, um problema já se faz perceber de antemão. Um autor que justifica sua obra por meio de seu valor pedagógico e que busca torná-la equivalente a um munus rei publicae não poderia jamais julgar aceitável uma filosofia que tem como preceito a não participação do sábio na vida política. ${ }^{25}$ Ora, é mais ou menos nesses termos que Cícero faz ver a Torquato a inadequação da filosofia do Jardim para a formação do homem romano. Vale dizer que a personagem do principal interlocutor de Cícero no primeiro diálogo é calcada a partir do homem que em 50 a.C., ano em que se passa a cena, era praetor designatus, ou seja, viria a desempenhar uma magistratura no ano seguinte. Vejamos um interessante passo da argumentação ciceroniana:

\footnotetext{
${ }^{23}$ Cf. De finibus III, 7-9.

${ }^{24}$ Para um estudo mais aprofundado das analogias que existem entre a refutação do epicurismo, no livro II do De finibus, e crítica ao estocismo, no livro IV, cf. Lévy, C. La dialectique de Cicéron dans les livres II et IV du "De finibus". Revue des études latines. Paris, année 62, p. 111-127, 1984.

${ }^{25}$ Cf. De finibus I, 59 e Epicuro, Sententia Vaticana, 58.
} 
Pois bem, Torquato. De que modo, enfim, vês isto: que tu, com esse teu nome, teu engenho e glória, o que fazes, o que pensas, a que referes tuas aspirações, com vistas a que queres realizar o que pretendes, o que julgas, em suma, ser o mais excelente na vida, não ouses dizer em uma assembléia? Que mérito queres alcançar, no momento mesmo em que te investires da magistratura e subires à tribuna (pois tu deverás declarar publicamente o que observarás na execução da justiça, e até mesmo, talvez, caso bem te pareça, tu dirás algo a respeito dos teus antepassados e de ti próprio, conforme o costume tradicional), que mérito alcançarias, portanto, ao dizeres que nesta magistratura tu hás de tudo fazer com vistas ao prazer e que tu nada fizeste em tua vida senão com vistas ao prazer? "Acaso tu me julgas", tu dirias, "tão insano a ponto de falar desse modo diante de ignorantes?" Ora, diz essas mesmas coisas no tribunal ou, se temes o círculo dos que assistem, diz no Senado. Jamais o farás. Por que razão, senão porque se trata de um discurso torpe? E quanto a mim e Triário, tu estimas, portanto, que somos merecedores dessa linguagem torpe ? $^{26}$

A moral de Epicuro, baseada no prazer (mesmo com a conotação singular que o termo possa ter para esse filósofo), entra em contradição com a moral tradicional romana. Torquato, se quisesse seguir a filosofia que estuda e defende, ou deveria negar o mos maiorum, representado de modo tão glorioso por seus antepassados ${ }^{27} \mathrm{e}$, assim, fiel ao epicurismo, abster-se de desempenhar qualquer função pública, ou, por outro lado, ocupando um cargo na Vrbs, deveria esconder suas convicções e forjar uma persona que se apresentasse em público, vivendo em uma eterna contradição consigo mesmo. Pensaria uma coisa, diria outra. Na concepção da personagem de Cícero, ${ }^{28}$ portanto, a filosofia de Epicuro não serve à formação do homem público romano. $\mathrm{O}$ trecho que segue abaixo corrobora nossa interpretação:

\footnotetext{
${ }^{26}$ Cf. De finibus II, 74: Quid? illud, Torquate, quale tandem uidetur, te isto nomine, ingenio, gloria, quae facis, quae cogitas, quae contendis quo referas, cuius rei causa perficere quae conaris velis, quid optimum denique in uita iudices non audere in conventu dicere? quid enim mereri uelis, iam cum magistratum inieris et in contionem ascenderis - est enim tibi edicendum quae sis observaturus in iure dicendo, et fortasse etiam, si tibi erit visum, aliquid de maioribus tuis et de te ipso dices more maiorum, quid merearis igitur, ut dicas te in eo magistratu omnia uoluptatis causa facturum esse, teque nihil fecisse in uita nisi uoluptatis causa? 'An me', inquis, 'tam amentem putas, ut apud imperitos isto modo loquar?' At tu eadem ista dic in iudicio aut, si coronam times, dic in senatu. Numquam facies. Cur, nisi quod turpis oratio est? Mene ergo et Triarium dignos existimas, apud quos turpiter loquare?

${ }^{27}$ O sobrenome Torquatus, segundo o relato de Cícero, foi atribuído pela primeira vez a Tito Mânlio, chamado Imperiosus, que foi cônsul três vezes no século IV a.C.. Era renomado por sua extrema severidade e pelo rigor com que impunha a disciplina. Passou a ser chamado Torquatus por ter arrancado o colar (torquis), como troféu, a um gaulês inimigo que matou em um duelo no ano de 361 a. C..

${ }^{28}$ Convicção que é partilhada pela persona do autor que fala no proêmio do livro III (cf. De finibus III, 1). 
Observa, portanto, se não deverias te servir de nossas palavras e de teus pensamentos. Pois se forjasses um semblante, um andar, para que parecesses mais grave, não serias semelhante a ti mesmo. Palavras tu forjarias e dirias o que não pensas? Ou ainda, assim como roupas, tu terias um pensamento em casa e outro no fórum, de modo que teu semblante seja uma aparência, no interior se oculte a verdade? Observa, eu te peço, se isso é correto. A mim ao menos, parecem-me verdadeiras as opiniões que forem honrosas, as que forem dignas de louvor, as que forem plenas de glória, as que no Senado, as que diante do povo, as que em toda reunião e conselho devam ser proclamadas, para que não deixe de ser vergonhoso pensar o que é vergonhoso dizer. ${ }^{29}$

O caso do estoicismo é mais complexo. Se a moral do Pórtico não entra em contradição com o costume tradicional romano de modo tão evidente, a terminologia desenvolvida por esses filósofos, excessivamente rigorosa, faria com que eles chegassem a conclusões desconcertantes e criassem um modo de se expressar e de pensar que se mostraria incongruente com o senso comum. Assim, embora atribua valor à virtude e louve uma série de características que são também exaltadas pela moral tradicional romana, o estocismo não seria adequado como filosofia que pretendesse formar o cidadão romano, o homem público romano. A argumentação, nesse sentido, guarda semelhança com aquela que vimos ao tratarmos do epicurismo. Em importante passagem do livro IV do De finibus (a qual reproduzimos mais abaixo), a personagem de Cícero critica a terminologia inovadora de Zenão, autor que não faria senão chamar com outros nomes conceitos que já faziam parte da filosofia moral dos filósofos anteriores, os da Academia e do Liceu. É com tom extremamente irônico que a personagem de Cícero se refere ao fundador do estoicismo: "Que poderoso intelecto! Que motivo justo para o surgimento de uma nova doutrina!" ${ }^{30}$ Mais adiante, a personagem comenta, sem abandonar o tom irônico que domina toda a passagem, uma possível participação de um adepto do estoicismo na vida pública romana:

É essa, sem dúvida, a correção da filosofia dos antigos, a retificação, que não pode ter absolutamente nenhuma admissão na cidade, no fórum, na cúria! Pois quem poderia tolerar um homem que de tal forma se expressasse, que declarasse ser o propositor de uma vida a

\footnotetext{
${ }^{29}$ Cf. De finibus II, 77: Vide igitur ne non debeas uerbis nostris uti, sententiis tuis. quodsi uultum tibi, si incessum fingeres, quo grauior uiderere, non esses tui similis; uerba tu fingas et ea dicas, quae non sentias? aut etiam, ut uestitum, sic sententiam habeas aliam domesticam, aliam forensem, ut in fronte ostentatio sit, intus ueritas occultetur? Vide, quaeso, rectumne sit. mihi quidem eae uerae uidentur opiniones, quae honestae, quae laudabiles, quae gloriosae, quae in senatu, quae apud populum, quae in omni coetu concilioque profitendae sint, ne id non pudeat sentire, quod pudeat dicere.

${ }^{30} \mathrm{Cf}$. De finibus IV, 21: O magnam uim ingenii causamque iustam, cur noua existeret disciplina!
} 
ser vivida sábia e gravemente e, tendo o mesmo parecer de todos e atribuindo às mesmas coisas o mesmo significado, impusesse-lhes outros nomes, alterasse apenas os termos, nada subtraísse das opiniões? O patrono de uma causa, no epílogo, discursando em favor do réu, diria que não é um mal o exílio, ou a confiscação pública dos bens? Que coisa desse tipo deveria ser rejeitada, mas não evitada? E que não é necessário que o juiz seja misericordioso? Ora, e se falasse em uma assembleia, caso Aníbal tivesse chegado às portas da cidade e a muralha com uma lança ultrapassasse, ele diria que não se contam entre os males tornar-se cativo, ser vendido, ser assassinado, perder a pátria? Ou o senado, ao decretar a celebração de um triunfo em favor do Africano, poderia dizer: 'por sua virtude', ou 'ventura', se não se pode dizer verdadeiramente que haja virtude nem ventura em algum homem senão no sábio? Que filosofia é essa, portanto, que fala no fórum segundo o costume comum e, nos tratados, segundo um costume próprio? Sobretudo uma vez que naquilo que eles dão a entender com suas palavras não haja nenhuma inovação, mas persistam as mesmas coisas de outro modo? Pois que diferença há entre dizeres que as riquezas, o poder, a saúde são bens e dizeres que são 'coisas preferíveis', uma vez que aquele que as chama bens não lhes atribua nada mais do que tu que denominas as mesmas 'coisas preferíveis? ${ }^{31}$

Assim, de modo análogo ao que acontecia no caso do homem público epicureu, o representante do estoicismo que venha a participar da vida pública romana deverá ou servir-se de dois tipos de linguagem, uma íntima, outra pública, e assim estará sempre em contradição consigo mesmo, ou deverá ser fiel ao estoicismo e abandonar de modo radical o mos maiorum. Trata-se de uma filosofia cujo rigor moral excessivo, fruto de um excessivo e vicioso rigor terminológico, não serve à formação do homem público conforme o concebe Cícero.

Se no último diálogo (livro V), por outro lado, não encontramos esse tipo de argumentação, que desabone a pertinência pedagógica da filosofia dos ueteres philosophi, dos representantes da Academia e do Liceu, isso não significa que, ao fim

\footnotetext{
${ }^{31}$ Cf. De finibus IV, 22-23: Haec uidelicet est correctio philosophiae ueteris et emendatio, quae omnino aditum habere nullum potest in urbem, in forum, in curiam. quis enim ferre posset ita loquentem eum, qui se auctorem uitae graviter et sapienter agendae profiteretur, nomina rerum commutantem, cumque idem sentiret quod omnes, quibus rebus eandem uim tribueret, alia nomina inponentem, uerba modo mutantem, de opinionibus nihil detrahentem? patronusne causae in epilogo pro reo dicens negaret esse malum exilium, publicationem bonorum? haec reicienda esse, non fugienda? nec misericordem iudicem esse oportere? in contione autem si loqueretur, si Hannibal ad portas uenisset murumque iaculo traiecisset, negaret esse in malis capi, uenire, interfici, patriam amittere? an senatus, cum triumphum Africano decerneret, 'quod eius uirtute' aut 'felicitate' posset dicere, si neque uirtus in ullo nisi in sapiente nec felicitas uere dici potest? quae est igitur ista philosophia, quae communi more in foro loquitur, in libellis suo? praesertim cum, quod illi suis verbis significent, in eo nihil nouetur, [de ipsis rebus nihil mutetur] eaedem res maneant alio modo. quid enim interest, diuitias, opes, ualitudinem bona dicas anne praeposita, cum ille, qui ista bona dicit, nihilo plus iis tribuat quam tu, qui eadem illa praeposita nominas?
} 


\section{nuntius antiquus}

da obra, o autor considere que a solução proposta por Antíoco para a questão do sumo bem deva ser aceita sem nenhuma ressalva. ${ }^{32}$ Julgamos ter mostrado em outro texto que, por meio de uma hábil estratégia na composição do tratado, Cícero não permite ao leitor conhecer seu julgamento final a respeito dos princípios da moral. ${ }^{33}$ Pensamos, entretanto, que, se nenhuma restrição é feita ao pensamento acadêmico no que diz respeito à sua pertinência pedagógica, isso é um indício bastante razoável de que o autor considerasse esse gênero de filosofia como o mais adequado à formação do homem público. E sua pertinência pedagógica talvez se deva justamente ao fato de que tal filosofia não propõe soluções definitivas para as questões, mas tão somente modos adequados de tratá-las, modos que consigam chegar às soluções mais prováveis, que possam ser expressas ao grande público (já que não estão em contradição com o senso comum) e que possam servir ao homem de estado romano. Essa interpretação encontra respaldo em não poucas passagens da obra de Cícero, como, por exemplo, na seguinte: "pois esta eu sempre estimei ser a filosofia perfeita, a que fosse capaz de se tratar das mais importantes questões de modo copioso e ornado". ${ }^{34}$ Ora, a perfecta philosophia é frequentemente associada a procedimentos comuns à Academia e ao Liceu:

Assim, sempre me agradou o costume dos peripatéticos e da Academia de, a respeito de todas as questões, discorrer em favor das partes contrárias; e não por esta razão apenas: porque de outra maneira não seria possível em cada questão encontrar o que fosse parecido com a verdade, mas inclusive porque seria ele o mais importante exercício para o discurso. ${ }^{35}$

Quisemos, neste breve texto, tratando de alguns proêmios de obras filosóficas de Cícero, em que, dentre outras coisas, o autor se dispõe a justificar sua atividade, quer quando representado sob a forma de uma personagem (como na Academica), quer como persona que fala em primeira pessoa (como no De finibus), discutir o significado da argumentação que faz da obra de filosofia um munus rei publicae. De acordo com o que

\footnotetext{
${ }^{32}$ No livro V, atribui-se a Antíoco o pensamento, exposto por Pisão, que pretende conciliar a moral dos antigos acadêmicos e peripatéticos.

33 Trata-se do texto da comunicação que apresentamos no III Congreso internacional de filología y tradición clásicas, que teve lugar em Havana, Cuba, entre os dias 8 e 12 de dezembro de 2009. Intitulado "A presença de Cícero nos diálogos e nos proêmios do De finibus. A mimese no diálogo filosófico ciceroniano", esse texto será publicado em breve nas Actas do referido Congresso.

34 Cf. Tusculanae I, 7: Hanc enim perfectam philosophiam semper iudicaui quae de maximis quaestionibus copiose posset ornateque dicere.

${ }^{35}$ Cf. Tusculanae II, 9: Itaque mihi semper Peripateticorum Academiaque consuetudo de omnibus rebus in contrarias partis disserendi non ob eam causam solum placuit, quod aliter non posset quid in quaque re ueri simile esset inuenire, sed etiam quod esset ea maxuma dicendi exercitatio.
} 


\section{nuntius antiquus}

vimos, longe de ser apenas um artifício por meio do qual o autor conseguiria angariar a simpatia de seus leitores, trata-se de uma declaração da função que pode exercer, no contexto da Roma século I a.C., a obra de filosofia escrita em latim; declaração que está em completo acordo com o projeto educacional que parece permear diversas obras do pensador romano e que, no De finibus ao menos, é um ponto fundamental nas discussões em que personagens romanas buscam definir qual seja o princípio moral mais próximo da verdade.

\section{Referências}

AUVRAY-ASSAYAS, C. Réécrire Platon? Les enjeux du dialogue chez Cicéron. In: COSSUTTA, F.; NARCY, M. (org.). La forme dialogue chez Platon. Grenoble: Jérôme Millon, 2001, p. 237-255.

BAILEY, C. Epicurus: the extant remains. Oxford: University Press, 1926.

BOYANCÉ, P. Études sur l'humanisme cicéronien. A collection of 18 articles previously published in periodicals. Brussels: Universa, 1970.

CICERO. Academica. Text revised and explained by J. S. Reid. Hildesheim: Georg Olms, 1984.

. De diuinatione. With an English translation by W. A. Falconer. London: Harvard University Press, 1992.

. De finibus bonorum et malorum. Recognouit breuique adnotatione critica instruxit L. D. Reynolds. Oxford: University Press, 1998.

. De natura deorum/ Academica. With an English translation by $\mathrm{H}$. Rackham. London: Harvard University Press, 1979.

Lettres, 1980 .

La république. Texte établi et traduit par Esther Bréguet. Paris: Les Belles

. On moral ends. Edited by Julia Annas. Translated by Raphael Woolf. Cambridge: University Press, 2001.

On the ideal orator. Translated with introduction, notes, appendixes, glossary and indexes by James M. May and Jakob Wisse. Oxford: University Press, 2001. 
University Press, 1988.

. Orator. With an English translation by H. M. Hubbell. London: Harvard . Tusculan disputations. With an English translation by J. E. King. London: Harvard University Press, 1989.

. De l'orateur. Texte établi et traduit par Edmond Courbaud. Paris: Les Belles Lettres, 1957.

. L'orateur; Du meilleur genre d'orateurs. Texte établi et traduit par Albert Yon. Paris: Les Belles Lettres, 1964.

. Traité du destin. Texte établi et traduit par Albert Yon. Paris: Les Belles Lettres, 1973.

DOUGLAS, A. E. Cicero the philosopher. In: DOREY, T. A. (org.). Cicero. New York: Basic Books, 1965, p. 135-170.

ÉPICURE. Lettres et maximes. Texte établi et traduit par Marcel Conche. Paris: Presses Universitaires de France, 1987.

GIANCOTTI, F. Profilo interiore del "De finibus". Atti del I Congresso internazionale di studi ciceroniani. Roma: Centro di studi ciceroniani editore, 1959. Vol. I, p. 223-244.

GIUSTA, M. Antioco di Ascalona e Carneade nel libro V del "De finibus bonorum et malorum" di Cicerone. Elenchos. Napoli, anno XI, fasc. 1, p. 29-49, 1990.

GRIFFIN, M. The composition of the "Academica": motives and versions. In: INWOOD, B.; MANSFELD, J. (org.). Assent \& argument. Studies in Cicero's academic books. Leiden/ New York: Brill, 1997, p. 1-35.

INWOOD, B. Rhetorica disputatio: the strategy of "De finibus" II. Apeiron. Austin, vol. 23, n. 4, p. 143-164,1990.

LÉVY, C. La dialectique de Cicéron dans les livres II et IV du "De finibus". Revue des études latines. Paris, année 62, p. 111-127, 1984.

de LIMA, Sidney Calheiros de. Aspectos do gênero dialógico no "De finibus" de Cícero. Tese de Doutorado inédita. Campinas: UNICAMP, 2009.

MURPHY, T. Cicero's first readers: epistolary evidence for the dissemination of his works. Classical Quarterly. Oxford, n. 48, p. 492-505, 1998. 
RUCH, M. Le préambule dans les oeuvres philosophiques de Cicéron. Paris: Les Belles Lettres, 1958.

SCHMIDT, P. L. Cicero's place in Roman philosophy: A study of his Prefaces. The Classical Journal. Chicago, n. 74, p. 115-127, 1978-79.

VALENTE, M. A ética estoica em Cícero. Caxias do Sul: EDUCS, 1984. 